Pierre Oster Soussovev, né en 1933. Ouvrages: Le champ de mai, (Gallimard, 1955), Solitude de la lumière (Gallimard, 1957). Un nom toujours nouveau (Gallimard, 1960), La grande année (Gallimard, 1964), Les diewx (Gallimard, 1970), Requêtes, version nouvelle, suivie de Pour un art poétique, ébauches (Le temps qu'il fait (1992), Saint John Perse, Alexis et Dorothée Leger (Babel éditeur, 1992).

\title{
La Terre
}

La terre, les rochers... Les rochers, les maisons, la nuit même,

La plaine, et la mer, fondent un savoir proche des murs.

Le soleil, lui, masque sa solitude avec la nudité des choses, Conjugue à la lumière éparse un grand feu dans un étroit Foyer... La plaine, et la mer. La prairie, les maisons... La campagne

Exalte en moi le plaisir de plier devant de souples roseaux, De rendre aux chiens les chemins que le vent revendique.

Et le matin par-dessus les haies porte le dieu du Tout,

Le cède à la présence antique à travers la demeure des plantes,

Dans les arbres, sous l'écorce et dans les fentes des tumulus, Sur les lèvres des morts,

Ah ! le matin de brèche en brèche

Mesure le ciel... Le vent souffle dans les arches.

Un autre feu,

Le feu de la pénombre occulte le soleil ! Un second dieu nous comble

Et ses dons, la nuit magnifiquement les découvre au jour.

Dans les vergers va les répandre! Et moi je dois décrire

La plaine avide, la mer aride; embrasser gloire et péril.

De la substance du sommeil naitront d'impatientes paroles,

De l'inconstance du sommeil! Les mots, déjà, diffus,

Je les refuse, ils m’appauvrissent. Ils nous détruiraient, infimes,

Si, bien qu'aux aguets, nous ne reposions; ne cessions,

Entre les maillons que le temps assemble, en deçà de la chaîne

Des vagues, après que la mer a découvert les toits, ne tentions d'avoir part

Au poème impossible - infini, banal... [...]

Guide obscur... C'est en l'admirant que je verse à la plaine,

Aux vergers (la nuit faillit, défaille; et nous la vénérons),

Aux pommiers (ils brillent !) un tribut de piété limpide.

Le vent, sur les friches, à l'affût des collines. Et, d'est

En ouest, des reflets nous escortent ! A côté du labyrinthe,

Retour de la mer. Le sable, ses remparts. La mer a l'éclat

Des lambeaux du manteau que le soleil déchirera: d'une étoffe,

D'une enveloppe transparente et l'herbe tremblante. Envol

De beaucoup plus qu'une volle ! Envol sans rien. [...] 